\title{
RISIKO PEMBIAYAAN DAN DETERMINANNYA PADA PERBANKAN SYARIAH DI INDONESIA
}

\author{
RISK OF FINANCE AND ITS DETERMINANTS AT SHARIA BANKING IN INDONESIA
}

\author{
Rahmat Budiman*1, Noer Azam Achsani**), dan Rifki Ismal $\left.{ }^{* * *}\right)$ \\ *) Departemen Surveilans Sistem Keuangan, Bank Indonesia \\ Jl. M. H. Thamrin No. 2, Jakarta Pusat 10350 \\ **) Sekolah Bisnis Institut Pertanian Bogor \\ Jl. Raya Pajajaran, Bogor 16151 \\ ${ }^{* * *}$ Departemen Ekonomi dan Keuangan Syariah, Bank Indonesia \\ Jl. M. H. Thamrin No. 2, Jakarta Pusat 10350
}

\begin{abstract}
One major problem of Islamic banking in Indonesia today is the high Non-Performing Financing (NPF) with its ratio amounted to $5.68 \%$ in June 2016. This paper aimed to identify and examine both macroeconomic and bank-specific factors affecting NPF ratio of Islamic banking. Particularly, it used the panel data regression method with a monthly data basis of eleven Islamic commercial banks in Indonesia. Furthermore, there were two periods examined i.e. from December 2011 to June 2016 (no specific restrictions on economic performance) and from February 2013 to January 2015 (restriction on economic performance). Technically, the dependent variable was NPF ratio (NPF) and the independent variables were Industrial Production Index (IPI), Real Sales Index (IPR), the difference between the BI Rate and inflation (BIREAL), the exchange rate of Rupiah against the US Dollar (EXR), the annual growth of financing (GFINY), the ratio of financing to total assets (FINTA), the Capital Adequacy Ratio $(C A R)$, Return on Assets ratio (ROA), the coverage of loan loss provision (CKPN), and the concentration of financing in the real estate sector (REFIN). The results showed that in the two periods examined, NPF was significantly influenced by the internal factors. In the first period, $N P F$ was significantly influenced by GFINY, CKPN, and REFIN while in the second period, $N P F$ was significantly influenced by CAR, ROA, CPKN, and REFIN. This shows that the quality of risk management implementation, profitability and capital are important factors in reducing the NPF ratio.
\end{abstract}

Keywords: financing risk, credit risk, Islamic banking, panel data, fixed effects model

\begin{abstract}
Abstrak: Salah satu permasalahan utama perbankan syariah di Indonesia saat ini adalah tingginya rasio Non-Performing Financing (NPF), yaitu per Juni 2016 sebesar 5,68\%. Penelitian ini bertujuan mengidentifikasi dan meneliti faktor-faktor yang memengaruhi rasio NPF perbankan syariah baik faktor makroekonomi maupun faktor spesifik bank. Penelitian ini menggunakan metode regresi data panel dengan data bulanan dari sebelas Bank Smum Syariah (BUS) di Indonesia. Terdapat dua periode data yang diteliti yaitu periode Desember 2011-Juni 2016 (tidak ada batasan tertentu pada kinerja perekonomian) dan periode Februari 2013-Januari 2015 (pada saat kinerja perekonomian sedang menurun). Secara teknis, variabel dependen menggunakan rasio NPF (NPF) dan variabel independen yang digunakan yaitu Industrial Production Index (IPI), Indeks Penjualan Riil (IPR), selisih antara BI Rate dan inflasi (BIREAL), nilai tukar Rupiah terhadap US Dollar (EXR), pertumbuhan pembiayaan tahunan (GFINY), rasio pembiayaan terhadap total aset (FINTA), rasio kecukupan modal (CAR), rasio Return on Assets (ROA), rasio kecukupan pencadangan (CKPN), dan konsentrasi pembiayaan pada sektor real estate (REFIN). Hasil penelitian menunjukkan bahwa rasio NPF untuk kedua periode tersebut lebih dipengaruhi oleh faktor spesifik bank dari pada faktor makroekonomi. Pada periode pertama, NPF dipengaruhi secara signifikan oleh variabel GFINY, CKPN, dan REFIN, sedangkan pada periode kedua, NPF dipengaruhi oleh CAR, ROA, CKPN, dan REFIN. Hal tersebut menunjukkan bahwa kualitas penerapan manajemen risiko pembiayaan serta kondisi profitabilitas dan permodalan bank merupakan faktor penting dalam upaya menurunkan rasio NPF.
\end{abstract}

Kata kunci: risiko pembiayaan, risiko kredit, perbankan syariah, data panel, model efek tetap

${ }^{1}$ Alamat Korespondensi:

Email: rahmat.budiman@gmail.com 


\section{PENDAHULUAN}

Risiko perbankan yang paling esensial sebagai konsekuensi dari pelaksanaan fungsi intermediasi yaitu risiko kredit (credit risk) atau dalam istilah perbankan syariah sering juga disebut sebagai risiko pembiayaan (financing risk). Risiko kredit merupakan potensi kerugian bagibankyang terjadiketika nasabah peminjam (debitur) atau nasabah yang menerima pembiayaan tidak dapat membayar kewajibannya kepada bank. Risiko kredit merupakan sumber risiko yang paling dominan di industri perbankan, baik perbankan syariah maupun konvensional (Sundararajan, 2004).

Indikator yang paling sering digunakan untuk mengukur tingkat risiko kredit adalah rasio Non Performing Loan (NPL) untuk perbankan konvensional atau Non Performing Financing (NPF) untuk perbankan syariah. Perkembangan rasio NPF Bank Umum Syariah (BUS) lebih tinggi dari pada rasio NPL Bank Umum Konvensional (BUK) sebagaimana terlihat pada Gambar 1. Sejak Maret 2010 sampai dengan Juni 2016, secara agregat, rasio NPF BUS selalu lebih besar dari pada rasio NPL BUK. Bahkan, dalam dua tahun terakhir, rasio NPF BUS mencapai hampir dua kali lipat dari rasio NPL BUK. Pada posisi Juni 2016, rasio NPF BUS mencapai 5,68\% sementara rasio NPL BUK hanya sebesar $2,95 \%$.
Data tersebut menunjukkan suatu gejala yang cukup mengkhawatirkan mengenai risiko pembiayaan perbankan syariah di Indonesia. Kekhawatiran itu didasarkan pada kondisi bahwa kinerja rasio NPF perbankan syariah dapat mengirimkan sinyal yang lebih cepat mengenai terjadinya krisis keuangan dibandingkan perbankan konvensional (Adebola et al. 2011). Hal tersebut sangat wajar karena perbankan syariah antara lain menggunakan konsep bagi hasil (profit and loss sharing) dari pada konsep bunga (riba). Di samping itu, perbankan syariah juga memiliki prinsip bahwa semua transaksi harus didasarkan pada transaksi ekonomi yang riil dan melibatkan aset yang berwujud (Beck et al. 2012). Dengan demikian, melihat rasio NPF yang relatif tinggi tersebut, terdapat indikasi yang cukup kuat bahwa kinerja sektor riil saat ini sedang mengalami penurunan.

Permasalahan pada sektor riil akan berpengaruh pada permasalahan di sektor keuangan khususnya perbankan. Hal tersebut karena sangat banyak pelaku usaha maupun rumah tangga yang memperoleh fasilitas pembiayaan dari perbankan. Berbagai permasalahan makroekonomi mengakibatkan terjadinya penurunan daya beli dan penurunan kemampuan membayar (repayment capacity) masyarakat terhadap kewajiban kepada perbankan dan pada akhirnya berdampak pada peningkatan risiko pembiayaan perbankan syariah.

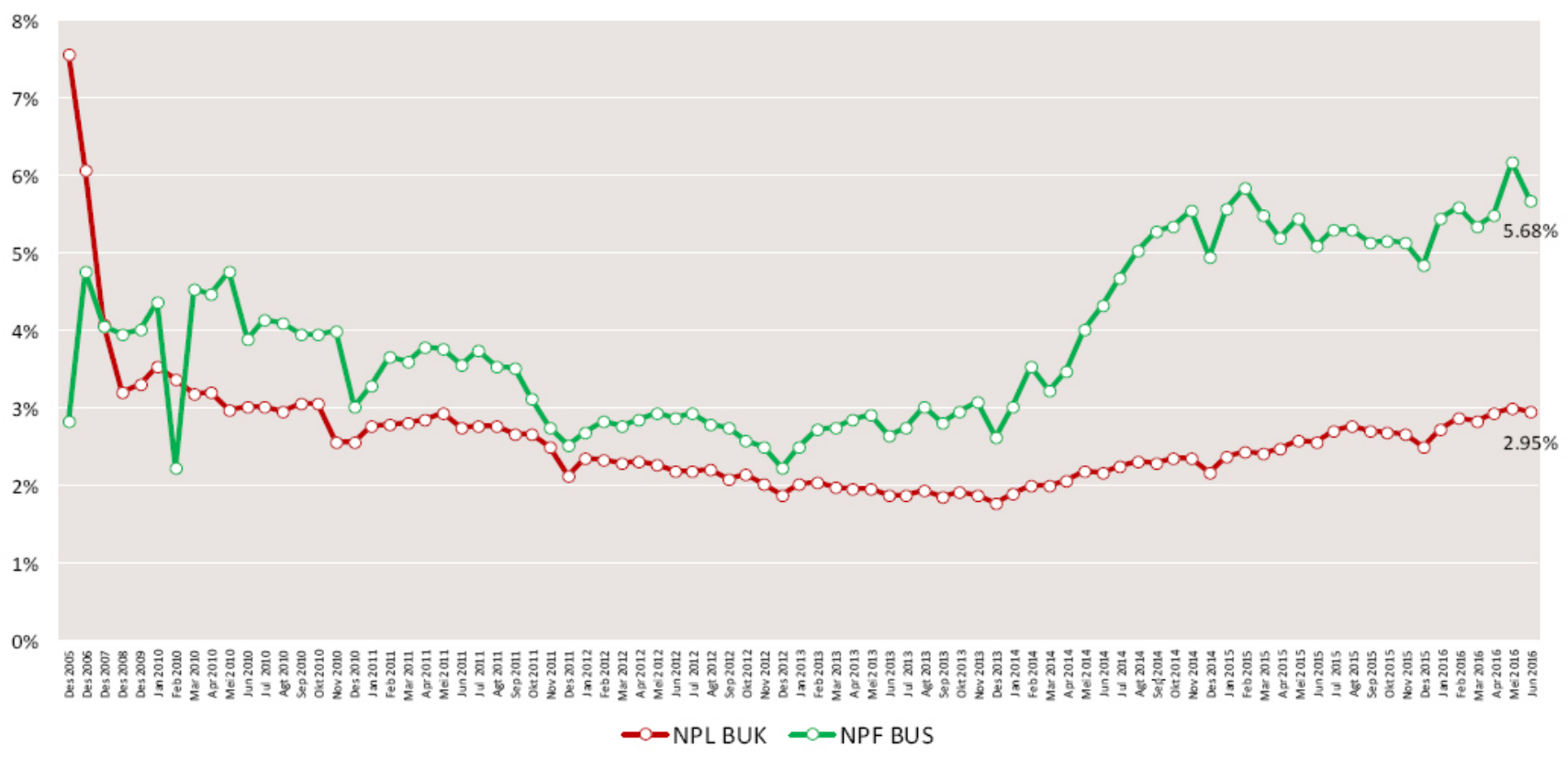

Gambar 1. Perkembangan Rasio NPL BUK dan NPF BUS (Bank Indonesia dan Otoritas Jasa Keuangan) 
Secara individual, dampak penurunan sektor riil akan dirasakan berbeda untuk setiap bank syariah. Faktanya, beberapa bank syariah dapat menjaga rasio NPF pada tingkat yang relatif kecil. Fakta tersebut menunjukkan bahwa variabel spesifik individual bank juga memiliki pengaruh tersendiri terhadap rasio NPF.

Penelitian ini bertujuan melakukan analisis mengenai hubungan dan signifikansi pengaruh variabel makroekonomi (eksternal) dan variabel spesifik bank (internal) terhadap risiko pembiayaan industri perbankan syariah (yang diwakili oleh sebelas BUS) baik dalam periode secara umum (tanpa pembatasan tertentu) maupun pada saat kinerja perekonomian sedang menurun. Di samping itu, penelitian ini juga mengusulkan rekomendasi kebijakan manajemen risiko yang dapat dilakukan oleh perbankan syariah dan regulator agar risiko pembiayaan tetap terjaga pada tingkat yang relatif rendah.

\section{METODE PENELITIAN}

Data yang digunakan dalam penelitian ini terdiri dari data makroekonomi dan data spesifik bank secara individual. Data makroenomi diperoleh dari publikasi dan statistik yang diterbitkan oleh BI, sedangkan data varianbel spesifik bank diperoleh dari laporan bank secara individual yang disampaikan kepada BI secara online. Di samping itu, terdapat data hasil olahan Otoritas Jasa Keuangan (OJK) khususnya data kinerja perbankan yaitu data rasio NPF, CAR, dan ROA.

Perbankan syariah sebagai objek penelitian ini diwakili oleh 11 BUS, yaitu PT Bank Syariah Mandiri, PT Bank Syariah Muamalat Indonesia, PT Bank Rakyat Indonesia Syariah, PT Bank Negara Indonesia Syariah, PT Bank Mega Syariah, PT Bank Jabar Banten Syariah, PT Bank Syariah Bukopin, PT Bank Panin Syariah, PT Bank Central Asia Syariah, PT Maybank Indonesia Syariah, dan PT Bank Victoria Syariah. Adapun horison time series mengambil dua periode waktu sesuai dengan tujuan penelitian. Periode yang pertama, yaitu dari bulan Desember 2011-Juni 2016 secara bulanan (55 bulan), yaitu kurun waktu tanpa pembatasan tertentu. Periode yang kedua, yaitu dari Februari 2013-Januari 2015 (24 bulan) yaitu dengan pembatasan pada saat kinerja perekonomian sedang menurun.

Pendekatan penelitian yaitu berupa penelitian data sekunder. Penelitian diawali dengan pernyataan teori yang menggambarkan hubungan antar variabel ekonomi yang akan dianalisis berdasarkan teori ekonomi yang cocok dan diyakini mampu menjelaskan perilaku fenomena ekonomi yang akan dianalisis. Pernyataan ekonomi tersebut selanjutnya dituliskan dalam bentuk model teoretis dengan pendekatan ekonometrika. Selanjutnya, data dari variabel-variabel penelitian dikumpulkan dari berbagai sumber.

Tahap selanjutnya adalah melakukan estimasi model menggunakan metode regresi data panel. Dari segi jenis data, regresi data panel memiliki jenis data cross section dan time series (Baltagi (2002), Greene (2003) Gujarati dan Porter (2009)). Sifat cross section data ditunjukkan oleh data yang terdiri lebih dari satu entitas (individu), sedangkan sifat time series ditunjukkan oleh setiap individu memiliki lebih dari satu pengamatan waktu (periode).

Adapun tahapan regresi data panel adalah sebagai berikut: Melakukan estimasi model dengan tiga alternatif pendekatan, yaitu Pooled Least Square (PLS), Fixed Effects Model (FEM), dan Random Effects Model (REM). Selanjutnya, melakukan pemilihan model melalui pengujian, yaitu Chow Test (memilih antara model PLS dan FEM), Hausman Test (memilih antara model FEM dan REM), dan Lagrange Multiplier (LM) Test (memilih antara model PLS dan REM). Melakukan pengujian asumsi dan kesesuaian model khususnya pengujian terhadap multikolinearitas dan heteroskedastisitas. Terakhir, interpretasi hasil model empiris, yaitu dari persamaan regresi, hasil uji $\mathrm{F}$, uji t, $\mathrm{R}^{2}$, dan adjusted $\mathrm{R}^{2}$.

Adapun pengolahan data dilakukan dengan menggunakan software Stata 13.0 dan Microsoft Excel. Berdasarkan pengujian awal pada data perbankan syariah untuk melihat hubungan antara variabel dependen dan variabel independen, diperoleh persamaan umum model NPF sebagai berikut:

$$
\begin{aligned}
\text { NPF }_{\mathrm{i}, \mathrm{t}} & \alpha+\beta_{1} \operatorname{IPI}_{\mathrm{i}, \mathrm{t}}+\beta_{2} \operatorname{IPR}_{\mathrm{i}, \mathrm{t}}+\beta_{3} \text { BIREAL }_{\mathrm{i}, \mathrm{t}}+\beta_{4} \mathrm{EXR}_{\mathrm{i}, \mathrm{t}}+ \\
& \beta_{5} \mathrm{GFINY}_{\mathrm{i}, \mathrm{t}}+\beta_{6} \mathrm{FINTA}_{\mathrm{i}, \mathrm{t}}+\beta_{7} \operatorname{CAR}_{\mathrm{i}, \mathrm{t}}+\beta_{8} \operatorname{ROA}_{\mathrm{i}, \mathrm{t}}+ \\
& \beta_{9} \mathrm{CKPN}_{\mathrm{i}, \mathrm{t}}+\beta_{10} \operatorname{REFIN~}_{\mathrm{i}, \mathrm{t}}+\mathrm{u}_{\mathrm{i}, \mathrm{t}}
\end{aligned}
$$

Keterangan: $\mathrm{NPF}_{\mathrm{i}, \mathrm{t}}$ (Rasio NPF bank i pada bulan ke-t); $\alpha$ (Intersep); IPI ${ }_{i, t}$ (Persentase pertumbuhan IPI tahunan untuk posisi $\mathrm{t}$ ); $\mathrm{IPR}_{\mathrm{i}, \mathrm{t}}$ (Persentase pertumbuhan IPR tahunan untuk posisi $\mathrm{t}$ ); BIREAL $_{\mathrm{i}, \mathrm{t}}$ (Selisih antara $\mathrm{BI}$ rate dikurang inflasi untuk posisi $t ; \mathrm{EXR}_{\mathrm{i}, \mathrm{t}}$ (Persentase perubahan nilai tukar Rupiah terhadap US Dollar 
bulanan (month to month) untuk posisi t); GFINY (Persentase pertumbuhan pembiayaan tahunan bank i periode ke-t); FINTA $_{\mathrm{i}, \mathrm{t}}$ (Rasio Pembiayaan terhadap Total Aset bank i periode ke-t); $\mathrm{CAR}_{\mathrm{i}, \mathrm{t}}$ (Rasio CAR bank i periode ke-t); $\mathrm{ROA}_{\mathrm{i}, \mathrm{t}}$ (Rasio ROA bank i periode ke-t); CKPN $_{\mathrm{i}, \mathrm{t}}$ (Rasio CKPN Pembiayaan terhadap total Pembiayaan bank i periode ke-t); $\operatorname{REFIN}_{\mathrm{i}, \mathrm{t}}$ (Porsi Pembiayaan pada sektor real estate terhadap Total Pembiayaan bank i periode ke- $\mathrm{t}) ; \mathrm{u}_{\mathrm{i}, \mathrm{t}}$ (Variabel gangguan (error) bank i periode ke-t).

Kerangka pemikiran dari penelitian ini dapat digambarkan sebagaimana Gambar 2.

\section{HASIL}

\section{Profil rasio NPF BUS}

Tren rasio NPF BUS secara agregat terus mengalami peningkatan terutama setelah Desember 2012. Rasio NPF BUS tertinggi terjadi pada bulan Mei 2016 yaitu sebesar 6,17\%. Sementara itu, per Juni 2016 rasio NPF BUS adalah sebesar 5,68\%. Adapun profil rasio NPF BUS per Juni 2016 adalah sebagaimana Gambar 3.

Dari gambar tersebut antara lain terlihat bahwa terdapat lima BUS yang memiliki rasio NPF di atas 5\% yang menyebabkan rasio NPF BUS secara agregat mencapai 5,68\%. Salah satu sumber risiko pembiayaan untuk kelima BUS tersebut adalah relatif tingginya konsentrasi pembiayaan pada sektor tertentu. Beberapa sektor yang perlu perhatian antara lain sektor pertambangan dan penggalian; sektor perdagangan besar dan eceran; sektor listrik, air, dan gas; dan sektor industri pengolahan. Di samping itu, beberapa BUS juga memiliki tingkat konsentrasi yang relatif tinggi terhadap debitur inti. Hasil estimasi data panel dengan pendekatan PLS, FEM, dan REM dapat dilihat pada Tabel 1.

\section{Uji Pemilihan Model}

Berdasarkan hasil Chow Test, Hausman Test, dan LM Test, untuk periode pertama (Model 1), model terpilih adalah model FEM. Selanjutnya, uji-F (Prob $>$ F) pada model FEM bernilai 0,0000 (lebih kecil dari $\alpha$ 0,05). Hal tersebut menunjukkan bahwa secara bersamasama koefisien regresi memiliki nilai yang signifikan berbeda dari nol sehingga dapat disimpulkan bahwa secara keseluruhan model cukup baik. Sementara itu, uji-t $(\mathrm{P}>|\mathrm{t}|)$ yang menguji signifikansi koefisien masing-masing variabel independen menunjukkan bahwa pada tingkat kepercayaan 95\%, variabel BIREAL, GFINY, CAR, ROA, CKPN, dan REFIN signifikan berpengaruh terhadap variabel NPF. Adapun nilai adjusted R-Squared sebesar 0,9005 menunjukkan bahwa $90,05 \%$ variabilitas NPF dapat dijelaskan oleh varibel-variabel independen.

Untuk periode kedua (Model 2), model terpilih juga adalah model FEM. Nilai Prob $>$ Chi2 juga sebesar 0,0000 (lebih kecil dari $\alpha$ 0,05) sehingga secara bersama-sama koefisien regresi memiliki nilai yang signifikan berbeda dari nol. Sementara itu, uji-t $(\mathrm{P}>|\mathrm{t}|)$ menunjukkan bahwa variabel-variabel yang secara signifikan berpengaruh terhadap NPF pada tingkat kepercayaan 95\% yaitu BIREAL, FINTA, CAR, ROA, CKPN, dan REFIN. Adapun nilai adjusted R-Squared sebesar 0,4332 .

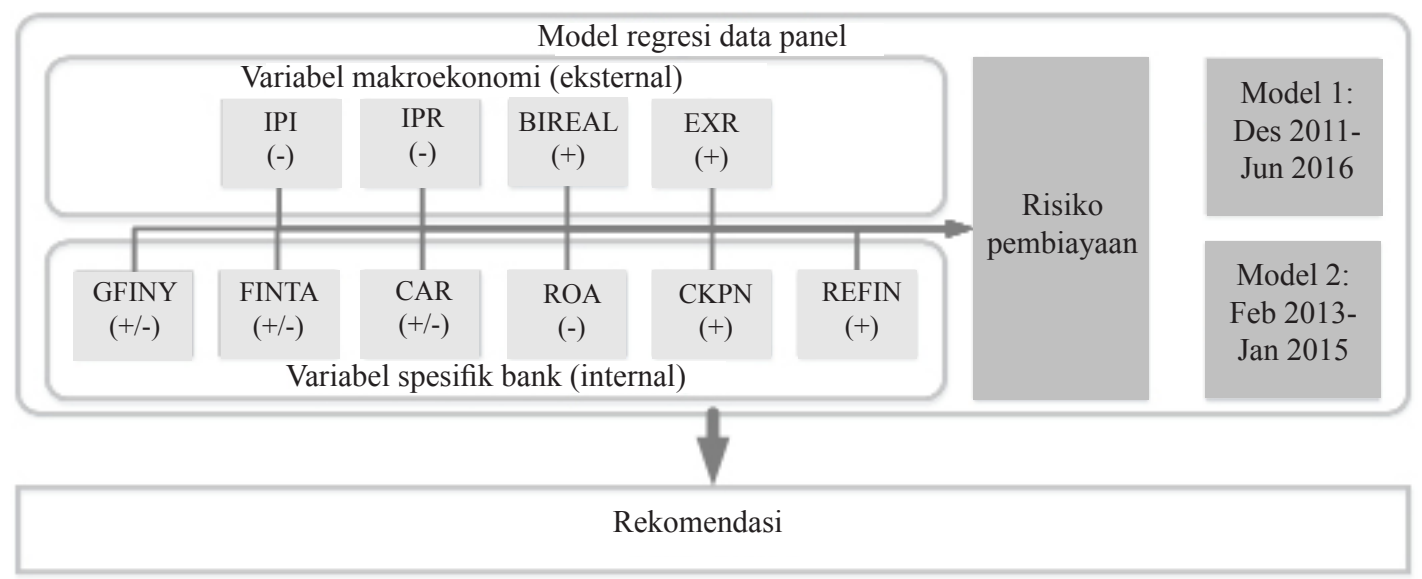

Gambar 2. Kerangka pemikiran penelitian 


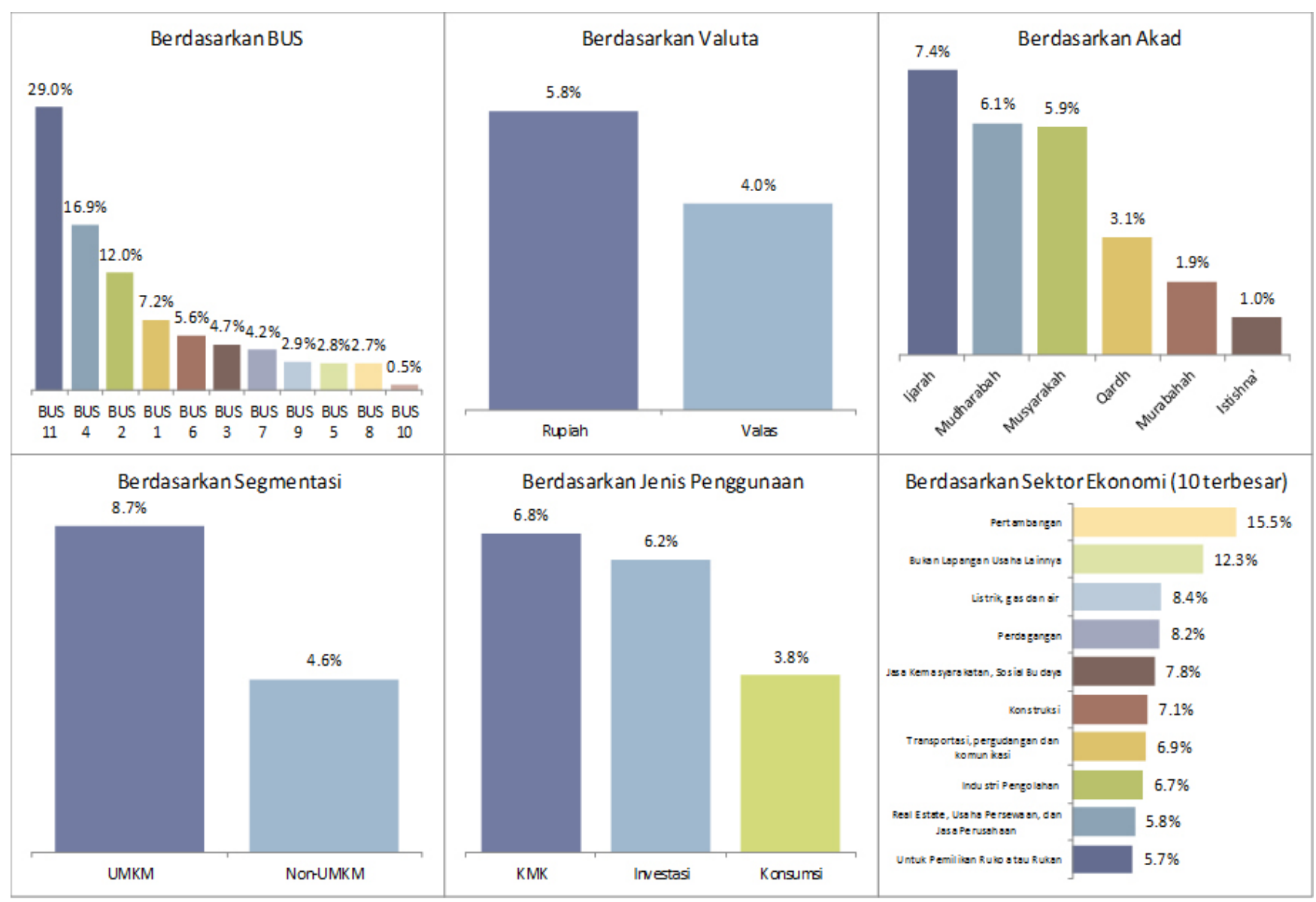

Gambar 3. Profil NPF BUS per Juni 2016

Tabel 1. Perbandingan hasil estimasi dengan pendekatan PLS, FEM, dan REM

\begin{tabular}{lrrrrrr}
\hline \multirow{2}{*}{ Variabel } & \multicolumn{2}{c}{ Model 1 (periode Desember 2011 - Juli 2016) } & \multicolumn{2}{c}{ Model 1 (periode Februari 2013 - Januari 2015) } \\
\cline { 2 - 7 } & \multicolumn{1}{c}{ pls } & \multicolumn{1}{c}{ fem } & \multicolumn{1}{c}{ rem } & \multicolumn{1}{c}{ pls } & \multicolumn{1}{c}{ fem } & \multicolumn{1}{c}{ rem } \\
\hline ipi & $-0,00275785$ & $-0,00202497$ & $-0,00229914$ & $-0,01697090$ & $-0,004422798$ & $-0,01104966$ \\
ipr & 0,00022477 & 0,00216870 & $-0,00057218$ & $-0,01798245$ & $-0,01375235$ & $-0,01596382$ \\
bireal & $0,15649850^{* * *}$ & $0,12989694^{* * *}$ & $0,17109296^{* * *}$ & $0,19482712^{* *}$ & $0,18846719^{* * *}$ & $0,19999854^{* * *}$ \\
exr & 0,00239147 & 0,00077474 & 0,00269623 & 0,01169060 & $-0,00154078$ & 0,00533032 \\
gfiny & $-0,00435693^{* * *}$ & $-0,00519601^{* * *}$ & $-0,00476090^{* * *}$ & $-0,01184189^{* * *}$ & $-0,00100855$ & $-0,00318031$ \\
finta & $-0,04378213^{* * *}$ & $-0,00507468$ & $-0,02146199^{*}$ & $-0,05608568^{* * *}$ & $-0,03128846^{*}$ & $-0,02747966$ \\
car & $-0,05916868^{* * *}$ & $-0,03563505^{* * *}$ & $-0,04318381^{* * *}$ & $-0,005824893^{* * *}$ & $-0,11626410^{* * *}$ & $-0,08746863^{* * *}$ \\
roa & $-0,11531181^{* * *}$ & $-0,0787443^{* *}$ & $-0,10636494^{* * *}$ & $-0,19215806^{* *}$ & $-0,22808645^{* * *}$ & $-0,20749560^{* * *}$ \\
ckpn & $1,12499480^{* * *}$ & $1,04027880^{* * *}$ & $1,06193760^{* * *}$ & $1,12531610^{* * *}$ & $0,69216774^{* * *}$ & $0,74620624 * * *$ \\
refin & $-0,01833911^{* * *}$ & $0,11869844^{* * *}$ & 0,00193255 & $-0,01339363^{*}$ & $0,00365147^{* * *}$ & $0,06539503^{* * *}$ \\
cons & $5,89270710^{* * * *}$ & 1,28515220 & $3,81900010^{* * *}$ & $7,42807010^{* * *}$ & $6,04518380^{* * *}$ & $5,58775930^{* * *}$ \\
\hline $\mathrm{N}$ & 605 & 605 & 605 & 264 & 264 & 264 \\
r2 & 0,87804714 & 0,90383154 & & 0,55180420 & 0,47628887 & \\
r2_a & 0,87599406 & 0,90053809 & & 0,534088995 & 0,43318507 & \\
\hline Ke & p & & & & &
\end{tabular}

Keterangan: * $\mathrm{p}<0,05 ; * * \mathrm{p}<0,01 ; * * * \mathrm{p}<0,001$ 


\section{Uji Asumsi Klasik}

Setelah terpilihnya model terbaik untuk kedua model tersebut, tahap selanjutnya adalah melakukan uji asumsi klasik yaitu uji multikolinearitas dan uji heteroskedastisitas. Berdasarkan uji multikolinearitas, kedua periode tersebut memiliki nilai korelasi di antara variabel independen yang relatif kecil $(<0,75)$. Untuk Model 1, nilai korelasinya berkisar antara 0,0012 dan 0,5710, sementara untuk Model 2, nilai korelasinya berkisar antara 0,0005 dan 0,6212. Di samping itu, nilai Variance Inflation Factor (VIF) untuk kedua periode tersebut masing-masing sebesar 3,99 dan 6,08 $(<10)$. Hal tersebut menunjukkan bahwa di antara variabel bebas tidak terdapat korelasi yang kuat atau tidak terjadi multikolinearitas.

Dari hasil uji heteroskedastisitas untuk model FEM baik pada Model 1 maupun Model 2 diperoleh nilai $\mathrm{P}$ Value (Prob>Chi2) sebesar 0,0000 yang menunjukkan bahwa estimasi model tersebut memiliki permasalahan heteroskedastisitas. Agar terbebas dari permasalahan heteroskedastisitas tersebut maka dipilih opsi robust pada saat regresi menggunakan pendekatan FEM sehingga diperoleh perbandingan hasil regresi FEM dan FEMrobust terlihat pada Tabel 2. Dengan opsi robust tersebut dan tingkat kepercayaan 95\%, maka variabel yang memengaruhi NPF secara signifikan untuk Model 1 adalah GFINY, CKPN, dan REFIN, sementara untuk Model 2 adalah CAR, ROA, CKPN, dan REFIN. Persamaan yang diperoleh dari model terpilih untuk Model 1 yaitu sebagai berikut:

$$
\begin{aligned}
\mathrm{NPF}_{\mathrm{i}, \mathrm{t}} & =1,28516220-0,00519601 * \mathrm{GFINY}_{\mathrm{i}, \mathrm{t}} \quad+ \\
1,04027880 * \mathrm{CKPN}_{\mathrm{i}, \mathrm{t}}+0,11869844 * \mathrm{REFIN}_{\mathrm{i}, \mathrm{t}} & +
\end{aligned}
$$

Sementara itu, persamaan dari model terpilih untuk Model 2 yaitu sebagai berikut:

$$
\begin{aligned}
\mathrm{NPF}_{\mathrm{i}, \mathrm{t}} & =6,04518380-0,11626410 * \mathrm{CAR}_{\mathrm{i}, \mathrm{t}}- \\
& 0,22808645 * \mathrm{ROA}_{\mathrm{i}, \mathrm{t}}+0,69216774 * \mathrm{CKPN}_{\mathrm{i}, \mathrm{t}}+ \\
& 0,11365147 * \mathrm{REFIN}_{\mathrm{i}, \mathrm{t}}
\end{aligned}
$$

Variabel IPI tidak berpengaruh secara signifikan terhadap NPF sehingga tidak sesuai dengan hipotesis awal. Hasil estimasi ini berbeda dengan hasil penelitian Nursechafia dan Abduh (2014) yang menyimpulkan bahwa variabel IPI berpengaruh negatif dan signifikan terhadap NPF. Variabel IPR tidak berpengaruh secara signifikan terhadap NPF sehingga tidak sesuai dengan hipotesis awal. Kemungkinan penyebabnya adalah karena nilai IPR diambil dari hasil survei di beberapa kota yang belum cukup representatif mewakili sektor riil, khususnya pedagang eceran, yang menjadi nasabah pembiayaan perbankan syariah.

Variabel BIREAL tidak berpengaruh secara signifikan terhadap NPF. Hal tersebut menunjukkan bahwa perubahan pricing, yang menjadi salah satu sumber risiko pembiayaan, di perbankan syariah Indonesia dalam jangka pendek tidak terlalu dipengaruhi oleh suku bunga kebijakan bank sentral. Walaupun sangat sulit untuk terbebas dari pengaruh bunga, namun diperlukan transmisi dan waktu tertentu agar perubahan suku bunga kebijakan pada akhirnya juga dapat memengaruhi perubahan biaya dana maupun imbal hasil pembiayaan pada perbankan syariah.

Variabel EXR juga tidak berpengaruh secara signifikan terhadap NPF. Hasil ini berbeda dengan hasil penelitian sebelumnya, yaitu Farhan et al. (2012); Khemraj dan Pasha (2014); serta Nursechafia dan Abduh (2014). Hal tersebut menunjukkan bahwa risiko pasar tidak terlalu memengaruhi risiko pembiayaan perbankan syariah. Kondisi tersebut sejalan dengan porsi pembiayaan dalam valuta asing di perbankan syariah yang relatif kecil yaitu per Juni 2016 hanya mencapai $\operatorname{Rp} 8,2$ triliun atau $5,2 \%$ dari total pembiayaan.

Variabel GFINY pada Model 1 menunjukkan hasil estimasi yang sesuai dengan hipotesis awal yaitu koefisien bertanda negatif dan berpengaruh secara signifikan terhadap NPF. Hasil estimasi ini sejalan dengan hasil penelitian sebelumnya oleh Khemraj dan Pasha (2009) dan Ahmad (2015). Hal tersebut menunjukkan bahwa peningkatan jumlah pembiayaan akan menurunkan rasio NPF dan sesuai dengan formulasi perhitungan rasio NPF itu sendiri. Dengan asumsi tidak ada penambahan pembiayaan bermasalah (sebagai pembilang), maka peningkatan jumlah pembiayaan (sebagai penyebut) akan menurunkan rasio NPF. Namun demikian, pada Model 2, GFINY tidak berpengaruh signifikan terhadap NPF.

Variabel FINTA tidak berpengaruh signifikan terhadap NPF baik pada Model 1 maupun Model 2. Dengan demikian, hasil estimasi ini tidak sejalan dengan penelitian sebelumnya Khemraj dan Pasha (2009); Misman (2012); Rahman dan Shahimi (2010); dan Tajuddin et al. (2009) yang menyimpulkan bahwa konsentrasi aset bank berupa portofilo pembiayaan berpengaruh secara signifikan terhadap NPF. 
Tabel 2.Perbandingan hasil estimasi dengan pendekatan FEM dan FEMrobust

\begin{tabular}{lrrrr}
\hline \multirow{2}{*}{ Variabel } & \multicolumn{2}{c}{ Model 1 (periode Desember 2011 - Juli 2016) } & \multicolumn{2}{c}{ Model 1 (periode Februari 2013 - Januari 2015) } \\
\cline { 2 - 5 } & \multicolumn{1}{c}{ fem } & \multicolumn{1}{c}{ femrobust } & \multicolumn{1}{c}{ femrobust } \\
\hline ipi & $-0,00202497$ & $-0,00202497$ & $-0,00442798$ & $-0,00442798$ \\
ipr & 0,00216870 & 0,00216870 & $-0,01375235$ & $-0,01375235$ \\
bireal & $0,12989694 * * *$ & 0,12989694 & $0,18846719^{* * *}$ & 0,18846719 \\
exr & 0,00077474 & 0,00077474 & $-0,00154078$ & $-0,00154078$ \\
gfiny & $-0,00519601 * * *$ & $-0,00519601 * * *$ & $-0,00100855$ & $-0,00100855$ \\
finta & $-0,00507468$ & $-0,00507468$ & $-0,03128846^{*}$ & $-0,03128846$ \\
car & $-0,03563505^{* * *}$ & $-0,03563505$ & $-0,11626410^{* * *}$ & $-0,11626410^{*}$ \\
roa & $-0,07897443^{* *}$ & $-0,07897443$ & $-0,22808645^{* * *}$ & $-0,22808645^{* *}$ \\
ckpn & $1,04027880^{* * *}$ & $1,04027880^{* * *}$ & $0,69216774^{* * *}$ & $0,69216774 * *$ \\
refin & $0,11869844 * * *$ & $0,11869844 * *$ & $0,11365147 * * *$ & $0,11365147^{*}$ \\
cons & 1,28516220 & 1,28516220 & $6,04518380^{* * *}$ & $6,04518380^{*}$ \\
\hline N & 605 & 605 & & 264 \\
r2 & 0,90383154 & 0,90383154 & 0,47628887 & 264 \\
r2_a & 0,90053809 & 0,90221254 & 0,43318507 & 0,47628887 \\
\hline
\end{tabular}

Keterangan: * $\mathrm{p}<0,05 ; * * \mathrm{p}<0,01 ; * * * \mathrm{p}<0,001$

Variabel CAR pada Model 1 tidak berpengaruh secara signifikan terhadap NPF. Hasil ini berbeda dengan hasil penelitian sebelumnya, yaitu Makri et al. (2013); Misman (2012); Rahman dan Shahimi (2010); dan Sukmana (2015). Kemungkinan penjelasannya adalah karena BUS di Indonesia dengan volume bisnis yang besar umumnya memiliki rasio CAR yang relatif rendah yang antara lain disebabkan oleh keterbatasan pemegang saham untuk melakukan penambahan modal. Namun, pada Model 2, CAR berpengaruh negatif dan signifikan terhadap NPF. Hal ini berarti bahwa bank yang tidak memiliki modal yang banyak, sementara harus tetap memberikan return kepada nasabah penyimpan, mereka cenderung akan menurunkan standar dalam penyaluran pembiayaan yang pada akhirnya berpotensi meningkatkan risiko pembiayaan. Hubungan yang berbanding terbalik ini juga mengacu pada pandangan bahwa bagi bank yang mampu meningkatkan modalnya, maka bank sebaiknya meningkatkan kapabilitasnya antara lain dalam bentuk sumber daya manusia yang handal dan teknologi informasi yang dapat mendukung aktivitas pembiayaan yang lebih baik sehingga risiko pembiayaan dapat terjaga pada tingkat yang rendah.

Variabel ROA pada Model 1 tidak berpengaruh secara signifikan terhadap NPF. Hasil ini berbeda dengan hasil penelitian sebelumnya, yaitu Setiawan dan Putri (2013) serta Messai dan Jouini (2013) yang menunjukkan bahwa bank dengan profitabilitas yang kecil akan meningkatkan risiko pembiayaan di masa mendatang. Namun demikian, pada Model 2, ROA berpengaruh negatif dan signifikan terhadap NPF. Hal tersebut mencerminkan bahwa perilaku bank dalam pengambilan risiko (risk taking behaviour) lebih terlihat pada waktu kondisi ekonomi sedang mengalami penurunan.

Variabel CKPN menunjukkan hasil estimasi yang juga sesuai dengan hipotesis awal yaitu koefisien bertanda positif dan berpengaruh secara signifikan terhadap NPF baik pada Model 1 maupun Model 2. Hal ini menunjukkan bahwa peningkatan nilai variabel CKPN akan meningkatkan rasio NPF, atau sebaliknya. Hasil estimasi ini mengkonfirmasi hasil penelitian sebelumnya, yaitu Messai dan Jouini (2013); Misman (2012); serta Ahmad (2015).

Variabel REFIN juga berpengaruh secara signifikan terhadap NPF baik pada Model 1 maupun Model 2 dengan tanda koefisien yang sama dengan hipotesis awal. Hasil estimasi ini mengkonfirmasi hasil penelitian sebelumnya yang dilakukan oleh Messai dan Jouini (2013); Misman (2012); serta Ahmad (2015).

\section{Rekomendasikan Kebijakan Manajemen Risiko}

Hasil estimasi dan analisis di atas dapat disimpulkan bahwa NPF perbankan syariah yang mencerminkan risiko pembiayaan lebih dipengaruhi oleh faktor-faktor internal dari pada faktor-faktor eksternal. Dengan memperhatikan determinan yang secara signifikan memengaruhi NPF, terdapat beberapa rekomendasi yang perlu dilakukan oleh perbankan syariah. Pertama, 
perbankan syariah perlu melakukan konsolidasi internal dan peningkatan efektivitas manajemen risiko pembiayaan, khususnya bagi BUS yang memiliki rasio NPF yang tinggi. Permasalahan yang terjadi pada lima BUS dengan rasio NPF yang tinggi disebabkan karena kelemahan penerapan manajemen risiko pembiayaan antara lain berupa konsentrasi yang terlalu tinggi pada sektor tertentu atau debitur inti tertentu. Di samping itu, perlu dilakukan evaluasi secara menyeluruh terhadap seluruh proses bisnis penyaluran pembiayaan serta memperbaiki kelemahan yang ditemukan.

Kedua, perbankan syariah seharusnya fokus pada penanganan pembiayaan bermasalah antara lain dengan mengintensifkan penagihan, restrukturisasi, sampai dengan penghapusbukuan. Hal tersebut dimaksudkan untuk menurunkan CKPN yang pada akhirnya diharapkan dapat menurunkan rasio NPF.

Ketiga, walaupun fokus pada penanganan pembiayaan bermasalah, perbankan syariah juga seharusnya tetap berupaya melakukan penyaluran pembiayaan secara lebih selektif. Pembiayaan harus tetap tumbuh dengan tetap memperhatikan prinsip kehati-hatian sehingga dapat menurunkan rasio NPF.

Keempat, perbankan syariah juga perlu meningkatkan efisiensi dan meningkatkan sumber pendapatan selain dari aktivitas pembiayaan. Selain menurunkan biaya CKPN, peningkatan efisiensi juga dapat dilakukan dengan penurunan biaya dana dan meningkatkan fee based income. Dengan demikian, diharapkan rasio ROA dapat meningkat sehingga pada akhirnya akan dapat menurunkan rasio NPF.

Kelima, perbankan syariah seharusnya dapat meningkatkan kapasitas permodalan yang saat ini dinilai relatif rendah. Rendahnya modal menyebabkan BUS menjadi kurang leluasa untuk membuka kantor cabang, ekspansi pembiayaan, mengembangkan infrastruktur, dan mengembangkan segmen layanan yang memiliki karakteristik risiko yang lebih bervariasi.

\section{Implikasi Manajerial}

Permasalahan di industri perbankan syariah bukan saja menjadi perhatian industri maupun BUS secara individual, namun juga menjadi perhatian dari otoritas. Beberapa permasalahan di atas juga menjadi isu strategis yang telah diidentifikasikan oleh OJK antara lain permasalahan rendahnya efisiensi dan permodalan.
Di samping itu, untuk mengembangkan perbankan syariah, baik otoritas, pemerintah, maupun stakeholder lainnya seharusnya memperkuat sinergi khususnya dalam menetapkan kebijakan. Hal tersebut diperlukan agar kebijakan yang ditetapkan oleh setiap otoritas memiliki visi dan arah yang sama, menghasilkan dampak yang lebih signifikan terhadap pengembangan perbankan syariah, serta tidak kontra-produktif satu sama lainnya.

\section{KESIMPULAN DAN SARAN}

\section{Kesimpulan}

Hasil pengolahan dan analisis data panel serta pengujian statistik, diperoleh kesimpulan bahwa determinan risiko pembiayaan perbankan syariah di Indonesia yang signifikan adalah faktor internal bank. Hasil ini mengkonfirmasi hasil penelitian Setiawan dan Putri (2013) yang menyimpulkan bahwa NPF perbankan syariah di Indonesia lebih banyak dipengaruhi oleh permasalahan manajemen internal bank dari pada faktor eksternal.

Dalam kondisi secara umum (tidak terdapat pembatasan waktu secara khusus) sebagaimana Model 1, rasio NPF perbankan syariah dipengaruhi oleh faktor-faktor internal yaitu variabel GFINY, CKPN, dan REFIN. Sedangkan faktor eksternal yaitu variabel IPI, IPR, BIREAL, dan EXR tidak berpergaruh signifikan terhadap NPF. Sementara itu, dalam kondisi kinerja perekonomian sedang menurun sebagaimana Model 2, perkembangan rasio NPF juga dipengaruhi faktor internal namun dengan beberapa variabel yang berbeda dengan Model 1. Pada model ini, rasio NPF dipengaruhi secara signifikan oleh variabel CAR, ROA, CKPN, dan REFIN. Sementara itu, pada model ini, variabel GFINY tidak berpengaruh signifikan terhadap NPF.

Berdasarkan determinan risiko pembiayaan yang berhasil diidentifikasi, terdapat beberapa rekomendasi yang dapat dilakukan oleh perbankan syariah, yaitu: i) melakukan konsolidasi internal dan peningkatan efektivitas manajemen risiko pembiayaan; ii) fokus pada penanganan pembiayaan bermasalah dalam rangka mengurangi pencadangan $(\mathrm{CKPN})$; iii) tetap berupaya melakukan penyaluran pembiayaan (GFINY) secara selektif dengan memperhatikan konsentrasi pada sektor-sektor yang berisiko tinggi khususnya sektor real estate (REFIN); iv) meningkatkan efisiensi dan 
meningkatkan sumber pendapatan selain dari aktivitas pembiayaan dalam rangka meningkatkan profitabilitas (ROA); dan v) meningkatkan kapasitas permodalan (CAR). Di samping itu, otoritas terkait perlu mengambil langkah-langkah yang lebih menyeluruh baik untuk pengembangan perbankan syariah secara umum maupun untuk menurunkan risiko pembiayaan secara khusus, dengan melakukan sinergi dengan pemerintah dan stakeholder lainnya.

\section{Saran}

Sebagai pengembangan dari penelitian ini, selanjutnya diperlukan penelitian berupa studi kasus terhadap bank secara individual menggunakan data primer. Penelitian tersebut memungkinkan untuk dapat menggunakan variabel lain yang lebih sesuai dengan karakteristik bank yang bersangkutan sehingga rekomendasi yang dihasilkan dapat secara langsung diimplementasikan.

\section{DAFTAR PUSTAKA}

Adebola SS, Yusoff WSbW, Dahalan J. 2011. An ARDL approach to the determinants of non-performing loans in Islamic banking system in Malaysia. Kuwait Chapter of Arabian Journal of Business and Management Review 1(2):20-30.

Ahmad NH. 2015. Impaired financing determinants of Islamic banks in Malaysia. Information Management and Business Review 7(3):17-25.

Baltagi BH. 2002. Econometric Analysis of Panel Data, second edition. New Jersey, United States: John Wiley \& Sons Ltd.

Beck T, Kunt AD, Merrouche O. 2012. Islamic vs. conventional banking: Business model, efficiency and stability. Journal of Banking \& Finance 37:433-447. https://doi.org/10.1016/j. jbankfin.2012.09.016.

Farhan M, Sattar A, Chaudhry AH, Khalil F. 2012. Economic determinants of non-performing loans: Perception of Pakistani bankers. European Journal of Business and Management 4(19):8799.
Greene WH. 2003. Econometric Analysis, Fifth Edition. New York: Prentice Hall.

Gujarati DN, Porter DC. 2009. Basic Econometrics, Fifth Edition. Boston: The McGraw-Hill Companies.

Khemraj T, Pasha S. 2009. The determinants of nonperforming loans: an econometric case study of Guyana. https://mpra.ub.uni-muenchen. de/53128/. [18 Juli 2015].

Makri V, Tsagkanos A, Bellas A. 2014. Determinants of non-performing loans: the case of Eurozone. Panoeconomicus 61(2):193-206. https://doi. org/10.2298/PAN1402193M.

MessaiAS, JouiniF. 2013. Microand macrodeterminants of non-performing loans. International Journal of Economics and Financial Issues 3(4):852860.

Misman FN. 2012. Financing structure, bank specific variables and credit risk: Malaysian Islamic banks. Journal of Business and Policy Research 7(1):102-114.

Nursechafia, Abduh M. 2014. The susceptibility of Islamic banks' creditrisk towards macroeconomic variables. Journal of Islamic Finance 3(1):2337. https://doi.org/10.12816/0031476.

Rahman AA, Shahimi S. 2010. Credit risk and financing structure of Malaysian Islamic banks. Journal of Economic Cooperation and Development 31(3):83-105.

Setiawan C, Putri ME. 2013. Non-performing financing and bank efficiency of Islamic banks in Indonesia. Journal of Islamic Finance and Business Research 2(1):58-76.

Sukmana R. 2015. Determinants of Non Performing Financing in Indonesian Islamic banks. Jeddah: Islamic Research and Training Institute (IRTI).

Sundararajan V. 2004. Risk measurement, risk management, and disclosure in Islamic finance. http://www.kantakji.com/media/9328/riskmeasurement-and-disclosure-in-islamic.pdf.[16 Desember 2016].

Tajuddin SNSA, Shahimi S, Hamid MA. 2009. Determinants of credit risk in Malaysian Islamic banks. Capital Market Review 17(1\&2):43-60. 